OPEN ACCESS

Edited by: André Dallmann,

Bayer, Germany

Reviewed by:

Raju Prasad Sharma, Leiden University, Netherlands

Steven Jan Van Cruchten, University of Antwerp, Belgium

*Correspondence: Florence Zeman florence.zeman@ineris.fr

Specialty section:

This article was submitted to Obstetric and Pediatric Pharmacology,

a section of the journal

Frontiers in Pediatrics

Received: 24 June 2021

Accepted: 24 August 2021 Published: 23 September 2021

Citation:

Personne S, Brochot C, Marcelo $P$. Corona A, Desmots S, Robidel F Lecomte A, Bach $V$ and Zeman F

(2021) Evaluation of Placental Transfer and Tissue Distribution of cis- and Trans-Permethrin in Pregnant Rats and Fetuses Using a

Physiological-Based Pharmacokinetic Model. Front. Pediatr. 9:730383. doi: 10.3389/fped.2021.730383

\section{Evaluation of Placental Transfer and Tissue Distribution of cis- and Trans-Permethrin in Pregnant Rats and Fetuses Using a Physiological-Based Pharmacokinetic Model}

\author{
Stéphane Personne ${ }^{1,2}$, Céline Brochot ${ }^{2}$, Paulo Marcelo ${ }^{3}$, Aurélie Corona ${ }^{1}$, \\ Sophie Desmots ${ }^{2}$, Franck Robidel ${ }^{2}$, Anthony Lecomte ${ }^{2}$, Véronique Bach ${ }^{1}$ and \\ Florence Zeman ${ }^{2 *}$
}

${ }^{1}$ Péritox, UMR_ 101, Université de Picardie Jules Verne, Amiens, France, ${ }^{2}$ Institut National de l'Environnement Industriel et des Risques (INERIS), Unité Toxicologie Expérimentale et Modélisation (TEAM), Parc ALATA BP2, Verneuil en Halatte, France, ${ }^{3}$ Plateforme ICAP, ICP FR CNRS 3085, Université de Picardie Jules Verne, Amiens, France

Biomonitoring studies have highlighted the exposure of pregnant women to pyrethroids based on the measurement of their metabolites in urine. Pyrethroids can cross the placental barrier and be distributed in the fetus as some pyrethroids were also measured in the meconium of newborns. Prenatal exposure to pyrethroids is suspected to alter the neurodevelopment of children, and animal studies have shown that early life exposure to permethrin, one of the most commonly used pyrethroid in household applications, can alter the brain development. This study aimed to characterize the fetal permethrin exposure throughout gestation in rats. We developed a pregnancy physiologically based pharmacokinetic (pPBPK) model that describes the maternal and fetal kinetics of the cis- and trans- isomers of permethrin during the whole gestation period. Pregnant Sprague-Dawley rats were exposed daily to permethrin $(50 \mathrm{mg} / \mathrm{kg}$ ) by oral route from the start of gestation to day 20. Permethrin isomers were quantified in the feces, kidney, mammary gland, fat, and placenta in dams and in both maternal and fetal blood, brain, and liver. Cis- and trans-permethrin were quantified in fetal blood and tissues, with higher concentrations for the cis-isomer. The pPBPK model was fitted to the toxicokinetic maternal and fetal data in a Bayesian framework. Several parameters were adjusted, such as hepatic clearances, partition coefficients, and intestinal absorption. Our work allowed to estimate the prenatal exposure to permethrin in rats, especially in the fetal brain, and to quantitatively estimate the placental transfer. These transfers could be extrapolated to humans and be incorporated in a human PPBPK model to estimate the fetal exposure to permethrin from biomonitoring data.

Keywords: pesticides, PBPK model, permethrin, pyrethroids, rat, pregnancy, fetus, brain 


\section{INTRODUCTION}

Pyrethroids are the most commonly used group of insecticides with a wide range of applications in agricultural, commercial, industrial, and residential settings. They are also used in veterinary and human medicine and for public health vector control (1). Given their broad spectrum of applications and the restriction of other classes of insecticides, their use has increased over the years, exposing a large population worldwide $(2,3)$. In humans, pyrethroids are rapidly metabolized in the gastro-intestinal tract and the liver and excreted as metabolites in urine (4). Permethrin metabolism involved hydrolysis by carboxylesterases and oxidation by cytochrome P450 enzymes. The exposure of human populations to pyrethroids is often based on the measurement of five urinary biomarkers: cis- and trans3-(2,2-dichlorovinyl)-2,2-dimethyl-(1-cyclopropane) carboxylic acid, 4-fluoro-3-phenoxybenzoic acid, 3-(2,2-dibromovinyl)-2,2dimethyl cyclopropane carboxylic acid, and 3-phenoxybenzoic acid (3-PBA). Biomonitoring studies in pregnant women have shown a widespread exposure to pyrethroids in many countries (5-11), which increased with the use of domestic insecticides (12). Pyrethroids can cross the placenta and have been measured in cord blood at delivery $(7,13,14)$ and in the meconium (15-17).

According to the Developmental Origin of Health and Disease hypothesis, exposure to environmental toxicants during fetal development and childhood can contribute to the development of chronic diseases, including neurodevelopmental disorders in later stages of life (18). The nervous system is particularly vulnerable during the critical window of prenatal development due to high cellular plasticity and the differentiation of neurons or glial cells at this stage (19). Fetal exposure to pyrethroids during this critical period of brain development is of concern and could impact child neurodevelopment (20). Associations between prenatal exposure to pyrethroids and child neurobehavioral disorders have been investigated in limited studies (21-28). A positive association between pyrethroid pesticides and autism spectrum disorder, attention deficit hyperactivity disorder, or neurocognitive development has only been observed in a few studies $(21,26,27)$. However, human exposure was based on the assessment of urinary metabolites, which can be common to several pyrethroids (29) and may not reflect the internal effective dose of the fetus in target tissues during critical time windows.

Among pyrethroids, permethrin [3-phenoxybenzyl (1RS, 3RS;1RS, 3SR)-cis, trans-3-(2,2-dichlorovinyl)-2,2dimethylcyclopropanecarboxylate] is one of the most frequently used pyrethroids $(30,31)$. Permethrin is composed of a mixture of cis- and trans-isomers. Experimental studies in rodents have shown that prenatal exposure to permethrin can alter neurodevelopment and cognitive abilities (32-36). To better understand the exposure dose-response relationship, it is critical to determine the concentration of the active compound in the brain, the target tissue. Physiologically based pharmacokinetic (PBPK) models can be used to simulate internal dosimetry from an external dose and can support the extrapolations between species based on the physiological and biochemical differences (37). PBPK models for permethrin have been developed in rats
(38-40) and humans at different life stages $(30,38,40-43)$ but did not cover prenatal life.

In this paper, we present the development of a pregnancy pPBPK model in rats to predict the kinetic of permethrin isomers in fetal tissues and their capacity to reach the developing brain. The proposed model is an extension of our previous PBPK model for permethrin in adult rats (38). An experimental toxicokinetic study was performed in pregnant rats after single and repeated dose administrations until the end of gestation. The measured concentrations in blood and several organs and tissues were used to calibrate the gestation PBPK model in a Bayesian framework.

\section{MATERIALS AND METHODS}

\section{Toxicokinetic Studies in Rats Chemicals}

Cis-permethrin and trans-permethrin were obtained from Dr. Ehrenstorfer (Augsburg, Germany). The internal standards, ${ }^{13} \mathrm{C}_{6}$-cis-permethrin and ${ }^{13} \mathrm{C}_{6}$-trans-permethrin, were purchased from Cambridge Isotope Laboratories (Andover, MA, USA).

For the toxicokinetic studies, permethrin in powder form (99\% purity, 40 and 60\% of cis and trans-isomers, respectively) was also purchased from Dr. Ehrenstorfer. Corn oil was acquired from Sigma-Aldrich (St. Quentin Fallavier, France).

\section{Animals and Experimental Design}

Our experimental protocol was approved by a regional ethics committee on experiments using animals (CREMEAP no. 96) and the French Ministry of Research with the permit number 01812.01. Sprague-Dawley female rats were housed with adult males overnight (Janvier Labs, Le Genest Saint Isle, France) after a minimum of 5 days of acclimatization. Mating was confirmed by a microscopic analysis of vaginal smears on the following morning. The day when a positive vaginal smear was observed was considered as day 0 of gestation. The female rats weighed $277 \pm 27 \mathrm{~g}$ [mean body weight (BW) \pm standard deviation (SD)] at day 0 . Each pregnant rat was housed in a cage with a $12-\mathrm{h}$ light/12-h dark cycle. Temperature and relative humidity were maintained at $22 \pm 2{ }^{\circ} \mathrm{C}$ and $55 \pm 15 \%$, respectively. The animals were provided with food (Altromin rodent diet for growing animals, Genestril, Royaucourt, France) and tap water ad libitum. The pregnant rats were dosed orally daily by gavage with 50 $\mathrm{mg} / \mathrm{kg}$ permethrin dissolved in corn oil $(2 \mathrm{ml} / \mathrm{kg}$ ) from the first day of gestation until the day of sacrifice at gestational day (GD) 1, GD15, or GD20. GD15 and GD20 were selected to characterize the kinetic profile in rats during the last week of pregnancy as the placental and conceptus weights increase exponentially during this period. Groups of four animals were sacrificed at 1, $2,3,4,6,10$, and $24 \mathrm{~h}$ post-dose by an overdose intra-peritoneal injection of pentobarbital at each gestational day. The dose of 50 $\mathrm{mg} / \mathrm{kg}$ (40:60 cis/trans), corresponding to 20 and $30 \mathrm{mg} / \mathrm{kg}$ of the cis- and trans-isomer, respectively, was similar to the $25 \mathrm{mg} / \mathrm{kg}$ dose used by Willemin et al. (38) in the same strain of rat. The mean body weights at GD15 and GD20 were $356 \pm 24$ and 422 $\pm 28 \mathrm{~g}$, respectively, and the mean number of fetuses per litter was $13.5 \pm 2$. 


\section{Sample Collection and Chemical Analyses}

At each time point, blood, whole brain, kidneys, liver, mammary glands, and abdominal fat were collected. For blood, formic acid (1\%) was added $\mathrm{v} / \mathrm{v}$ to blood to inhibit the metabolism of permethrin by carboxylesterases. At GD1 and GD15, the pregnant rats were kept in individual metabolic cages for $24 \mathrm{~h}$ to collect the feces. The placentas were collected at GD15 and GD20. Fetal blood, liver, and brain were collected at GD20. The placenta and fetal samples were pooled by litter to provide an adequate sample size for analysis. All samples were stored at $-80^{\circ} \mathrm{C}$ until analysis.

Extraction and analyses were performed by liquid chromatography-tandem mass spectrometry (LC-MS/MS) according to the analytical method developed by our team (44). Briefly, samples of $500 \mathrm{mg}$ were used except for mammary gland, fat, and feces, where a sample of $50 \mathrm{mg}$ was used. For blood, an aliquot of $1.5 \mathrm{ml}$ was used. The samples were transferred in vials and spiked with ${ }^{13} \mathrm{C}_{6}$-trans-permethrin as surrogate standard. Extraction was performed by liquid-liquid extraction using acetone/hexane $(2: 8, \mathrm{vol} / \mathrm{vol})$ with three consecutive extractions. The combined organic phases were evaporated to dryness under nitrogen before reconstitution for LC-MS/MS analysis. For fat, mammary gland, and feces, an additional purification step was performed using a blend of Sepra ZT-WAX and $\mathrm{Na}_{2} \mathrm{SO}_{4}$. All dried extracts were then reconstituted in $500 \mu \mathrm{L}$ of acetonitrile and transferred to autosampler vials with the addition of ${ }^{13} \mathrm{C}_{6}$-cis-permethrin as the internal standard. The analysis was conducted with an Acquity UPLC ${ }^{\circledR} \mathrm{H}$-Class (Waters) coupled to a triple quadrupole mass spectrometer Xevo TQ-S (Waters) with a HSS T3 column $(1.8 \mu \mathrm{m} ; 100 \mid 2.1 \mathrm{~mm}$, Waters). The limits of quantification (LOQs) for cis-permethrin were $4 \mathrm{ng} / \mathrm{g}$ in placenta and feces, $20 \mathrm{ng} / \mathrm{g}$ in the liver, brain, fat, and mammary gland, $40 \mathrm{ng} / \mathrm{g}$ in the kidneys, and $26 \mathrm{ng} / \mathrm{ml}$ in blood. The LOQs for trans-permethrin were $20 \mathrm{ng} / \mathrm{g}$ in the brain and placenta, $40 \mathrm{ng} / \mathrm{g}$ in feces, $80 \mathrm{ng} / \mathrm{g}$ in the liver, kidney, fat, and mammary gland, and $52 \mathrm{ng} / \mathrm{ml}$ in blood.

\section{Model Development} Model Structure

The adult male rat PBPK model for permethrin, as published by Willemin et al. (38), was extended to include gestation. The gestational PBPK model includes a maternal sub-model and a fetal sub-model that are linked via the placenta (Figure 1). The maternal sub-model includes the same 10 compartments as the adult male model by Willemin et al. (38) (blood, brain, liver, muscle, kidney, fat, stomach, intestinal lumen, and slowly perfused and rapidly perfused tissues) except that the testes compartment was removed and the mammary gland was added as a compartment. All the model equations can be found in the former paper. The fetal sub-model includes four compartments: blood, liver, brain, and a lumped compartment for the rest of the body. All fetuses from a single litter were modeled as one large fetal model.

In pregnant rats, oral absorption was modeled using a twocompartment model with the stomach and gastro-intestinal tract and a single constant of absorption $\left(K_{\mathrm{aI}}\right)$ located in the GI tract. Distribution in compartments was assumed to be limited

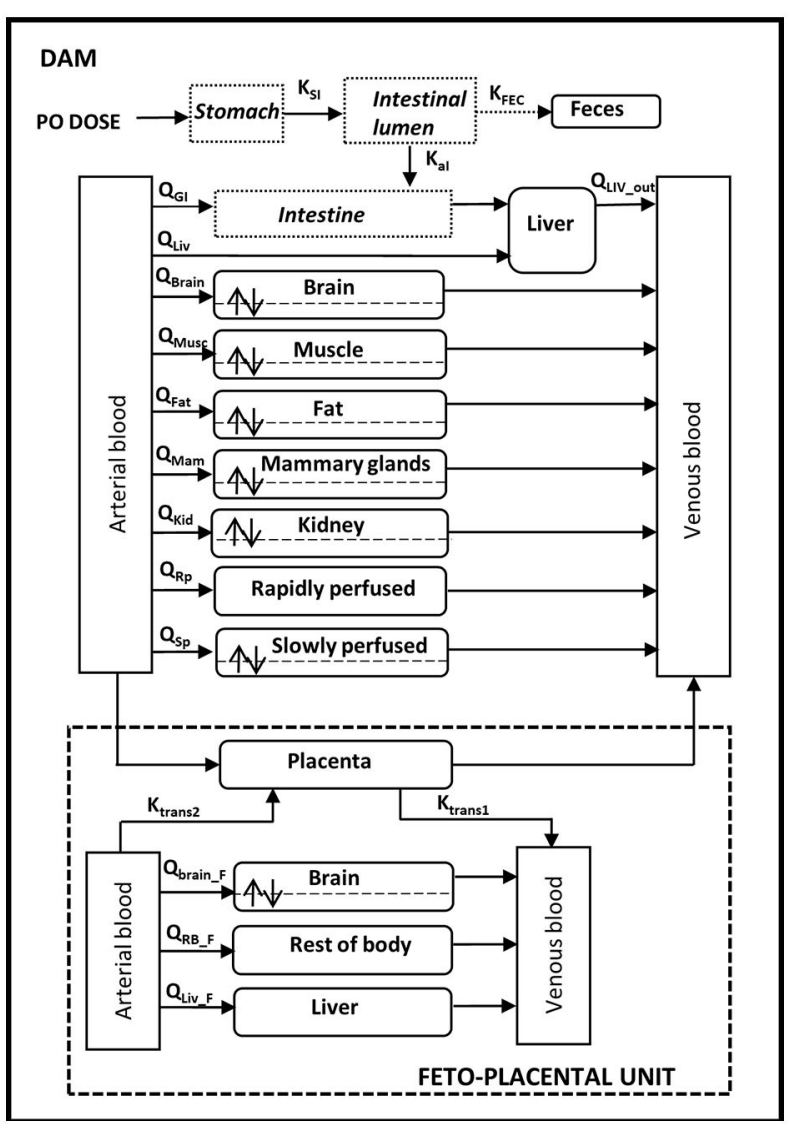

FIGURE 1 | Physiologically based pharmacokinetic model of cis- and trans-permethrin in pregnant rats and fetuses.

by diffusion in the brain, muscle, fat, kidney, slowly perfused tissues, and mammary tissues because of the lipophilicity of permethrin and of the experimental observations in animals. For the intestines, liver, rapidly perfused tissue, and placenta, the distribution was blood flow-limited. Similar to the adult model, permethrin is metabolized in blood and liver and excreted in feces. Fetal exposure was through the placenta with transfers described as bi-directional between the placenta and the fetal blood. Placental transfer was modeled as a diffusion process with a first-order rate constant (Ktrans1 and Ktrans2), and the amount of cis- or trans-permethrin in the placenta $\left(A_{\mathrm{Pla}}\right)$ was given by:

$$
\begin{aligned}
\frac{d\left(A_{P l a}\right)}{d t}=Q_{P l a} \times\left(C_{A r t}-\frac{C_{P l a}}{P C_{P l a}}\right) & -K t r a n s 1 \times \frac{C_{P l a}}{P C_{P l a}} \\
& +K t r a n s 2 \times C_{A r t, F}
\end{aligned}
$$

where $Q_{\text {Pla }}$ is the blood flow to the placenta, $C_{\text {Art }}$ and $C_{\mathrm{Pla}}$ are the maternal arterial and placental concentrations, $P C_{\mathrm{Pla}}$ is the placenta/blood partition coefficient, and $C_{\mathrm{Art}, \mathrm{F}}$ is the arterial concentration in the fetus. The distribution in fetal compartments was assumed to be flow-limited, with the exception of the brain. Fetal metabolism was assumed to be 
TABLE 1 | Physiological parameters of the maternal and fetal physiologically based pharmacokinetic models for cis- and trans-permethrin.

\begin{tabular}{|c|c|c|}
\hline Parameters & Value & Source \\
\hline \multicolumn{3}{|l|}{ Pregnant rats } \\
\hline Body weight (BW, kg) & $0.277-0.422^{\mathrm{a}}$ & This study \\
\hline \multicolumn{3}{|l|}{ Tissue volumes (fraction of initial BW, unitless) } \\
\hline Blood $\left(V_{\text {Blood }}\right)$ & 0.06 & Brown et al. (46) \\
\hline Muscle $\left(V_{\text {Musc }}\right)$ & 0.404 & Brown et al. (46) \\
\hline Brain $\left(V_{\text {Brain }}\right)$ & 0.0073 & Brown et al. (46) \\
\hline Kidney $\left(V_{\text {Kid }}\right)$ & 0.0076 & Brown et al. (46) \\
\hline Non-perfused $\left(V_{\mathrm{NP}}\right)$ & 0.05 & Brown et al. (46) \\
\hline Rapidly perfused $\left(V_{\mathrm{RP}}\right)$ & 0.046 & Brown et al. (46) \\
\hline Placenta $\left(V_{\mathrm{Pla}}\right)$ & $0-0.167^{a}$ & $\begin{array}{l}\text { Clewell (50); O'Flaherty et al. (51); Yoon et al. } \\
\text { (52) }\end{array}$ \\
\hline \multicolumn{3}{|c|}{ Blood flows (fraction of initial cardiac output, unitless) } \\
\hline Liver (total) $\left(Q_{\text {Livout }}\right)$ & 0.174 & Brown et al. (46) \\
\hline Portal (Gl tract) $\left(Q_{\mathrm{Gl}}\right)$ & 0.151 & Brown et al. (46) \\
\hline Arterial (Gl tract) (QLiv) & 0.024 & Brown et al. (46) \\
\hline Muscle $\left(Q_{\text {Musc }}\right)$ & 0.278 & Brown et al. (46) \\
\hline Brain $\left(Q_{\text {Brain }}\right)$ & 0.02 & Brown et al. (46) \\
\hline Kidney $\left(Q_{\text {Kid }}\right)$ & 0.141 & Brown et al. (46) \\
\hline Slowly perfused $\left(Q_{R p}\right)$ & 0.063 & Brown et al. (46) \\
\hline \multicolumn{3}{|l|}{ Blood volume (fraction of tissue, unitless) } \\
\hline Brain $\left(B V_{\text {Brain }}\right)$ & 0.03 & Brown et al. (46) \\
\hline Muscle (BV Musc $)$ & 0.04 & Tornero-Velez et al. (40) \\
\hline Kidney $\left(\mathrm{BV}_{\text {Kid }}\right)$ & 0.16 & Brown et al. (46) \\
\hline Fat $\left(B V_{\text {Fat }}\right)$ & 0.02 & Tornero-Velez et al. (40) \\
\hline Mammary glands (BV $\mathrm{Mam}_{\text {) }}$ & 0.02 & Assimilated to fat \\
\hline \multicolumn{3}{|l|}{ Fetuses } \\
\hline Body weight for individual fetus $\left(V_{1 \mathrm{Fet}}, \mathrm{kg}\right)$ & $0-0.0068^{a}$ & Sikov and Thomas (53) \\
\hline Cardiac output index $\left(\mathrm{QCl}_{1 \mathrm{~F}}, \mathrm{~L} / \mathrm{h} / \mathrm{kg}\right)$ & 22.8 & Girard et al. (54); Yoon et al. (52) \\
\hline \multicolumn{3}{|l|}{ Tissue volumes (fraction of BW) } \\
\hline Blood $\left(V_{\text {Blood_1F }}\right)$ & 0.0676 & Brown et al. (46) \\
\hline \multicolumn{3}{|l|}{ Tissue volume (changing during fetal growth, L) } \\
\hline Brain $\left(V_{\text {Brain_1F }}\right)$ & $0-0.0034$ & Sikov and Thomas (53) \\
\hline Liver $\left(V_{\text {Liv_1F }}\right)$ & $0-0.0044$ & Sikov and Thomas (53) \\
\hline Rest of the body $\left(V_{\mathrm{RB}_{-} 1 \mathrm{~F}}\right)$ & BW-sum of other tissue volumes & \\
\hline \multicolumn{3}{|l|}{ Tissue blood flow (fraction of cardiac output) } \\
\hline Brain (QBrain_1F $)$ & 0.1055 & Carter and Gu (55); Yoon et al. (52) \\
\hline
\end{tabular}


TABLE 1 | Continued

\begin{tabular}{|c|c|c|}
\hline Parameters & Value & Source \\
\hline Liver (QLiv_1F) & 0.061 & Itskovitz et al. (56); Yoon et al. (52) \\
\hline Rest of the body ( $\left.Q_{\mathrm{RB} \_1 \mathrm{~F}}\right)$ & Cardiac output-sum of other tissue blood flows & \\
\hline \multicolumn{3}{|l|}{ Blood volume (fraction of tissue) } \\
\hline Brain (BV Brain_1F $)$ & 0.03 & Set to adult value from Willemin et al. (38) \\
\hline Rest of the body ( $\left.\mathrm{BV}_{\mathrm{RB} \_1 \mathrm{~F}}\right)$ & 0.05 & Set to adult value from Willemin et al. (38) \\
\hline
\end{tabular}

${ }^{a}$ Range during the gestation period.

negligible. The model structure is identical for both isomers. The model code is provided in the Supplementary Material.

\section{Model Parameterization Physiological Parameters}

The physiological parameters (cardiac output, blood flow, and tissue volume) for the pregnant dam and the fetus are summarized in Table $\mathbf{1}$ and were obtained from the literature or measured in this study. The model accounted for the gestation-induced changes in maternal tissue volumes and fetal growth during the whole gestation period. The equations used for the growth of maternal and fetal tissues and also the changes in blood flows occurring during gestation can be found in Supplementary Table $\mathbf{S 1}$.

\section{Chemical Specific Parameters}

Chemical specific parameters for pregnant dams and fetuses were estimated using the measured concentrations in our toxicokinetic study, with the exception of the rate constants for absorption and for blood and intestinal metabolism. The parameters were estimated simultaneously in a Bayesian calibration framework using our experimental data. Separate calibrations were performed with data generated at GD1 or at GD15/GD20 after repeated daily administration. In a Bayesian approach, all parameters are considered as random variables. A prior distribution was defined for each parameter based on the knowledge on the values of the parameter. In conjunction with a likelihood function of the data, a posterior distribution was determined by random sampling methods (57).

For absorption, two metabolic rate constants are considered in the model: the intestinal absorption rate constant $\left(K_{\mathrm{aI}}\right)$ and the stomach-intestine transfer rate constant $\left(K_{\mathrm{SI}}\right)$. As it was not possible to estimate both parameters based on our experimental data, the $K_{\mathrm{aI}}$ values of the adult model of Willemin et al. (38) were used. Only the $K_{\text {sI }}$ values were estimated as $K_{\text {sI }}$ is considered as a sensitive parameter according to previous PBPK models published for pyrethroids (58). For metabolic clearances, as the liver is the main site of metabolism (59), only metabolic rate constants for permethrin isomers in the liver were estimated. Blood and intestinal rate constant values were set to the optimized values of the adult model of Willemin et al. (38).
A truncated normal distribution was assigned to the parameters for which values were reported in previous PBPK models for permethrin in adult rats $(38,40)$. The mean values of the prior distribution were taken from the PBPK model of Willemin et al. (38), with the exception of the liver clearance for which the values of the PBPK model of Tornero et al. (40) were used. For all other parameters, a uniform distribution was applied. The coefficients of variation were set to $50 \%$ for all parameters. The prior distributions of all parameters are reported in Table 2. The likelihood of the data was assumed to follow a lognormal distribution with $15 \%$ of error. The posterior distributions were estimated by Markov Chain Monte Carlo simulations using MCSim (ver.5.6.6) software. Three independent Markov chains of 10,000 iterations were run, and one in two of the last 4,000 iterations were recorded to check the convergence using the potential scale reduction factor $\hat{R}$. An acceptable convergence was considered as reached when the $\hat{R}$ value was 1.2 or less (60).

\section{Sensitivity Analyses}

A global sensitivity analysis (GSA) using the Sobol method was conducted on the PBPK model to identify the compound-specific parameters that have the most impact on the internal maternal and fetal exposures of permethrin (cis-isomer) following the same exposure scenario of the in vivo experiments. Three model outputs were selected: the arterial concentrations of the mother and the fetus and the concentration in the fetal brain. Truncated normal distributions were assigned to the specific compound parameters, with a mean estimated mean value (Table 2) and a coefficient of variation of $30 \%$. The SA was run at three time points at GD15 and GD20 (4, 6, and $12 \mathrm{~h}$ after the oral administration). The SA results are presented as two indices: the first order index, which is the variance contribution of one parameter to the total model variance, and the total order index, which is the result of the main effect of the parameter and of its interactions with the other parameters.

\section{RESULTS}

\section{Toxicokinetic Profiles in Pregnant Rats and Fetuses}

In pregnant rats, cis-permethrin was quantified in blood, feces, and all tissues after a single administration at GD1 and 
TABLE 2 | Distribution of the chemical specific parameters of the model for permethrin isomers in pregnant rats and fetuses.

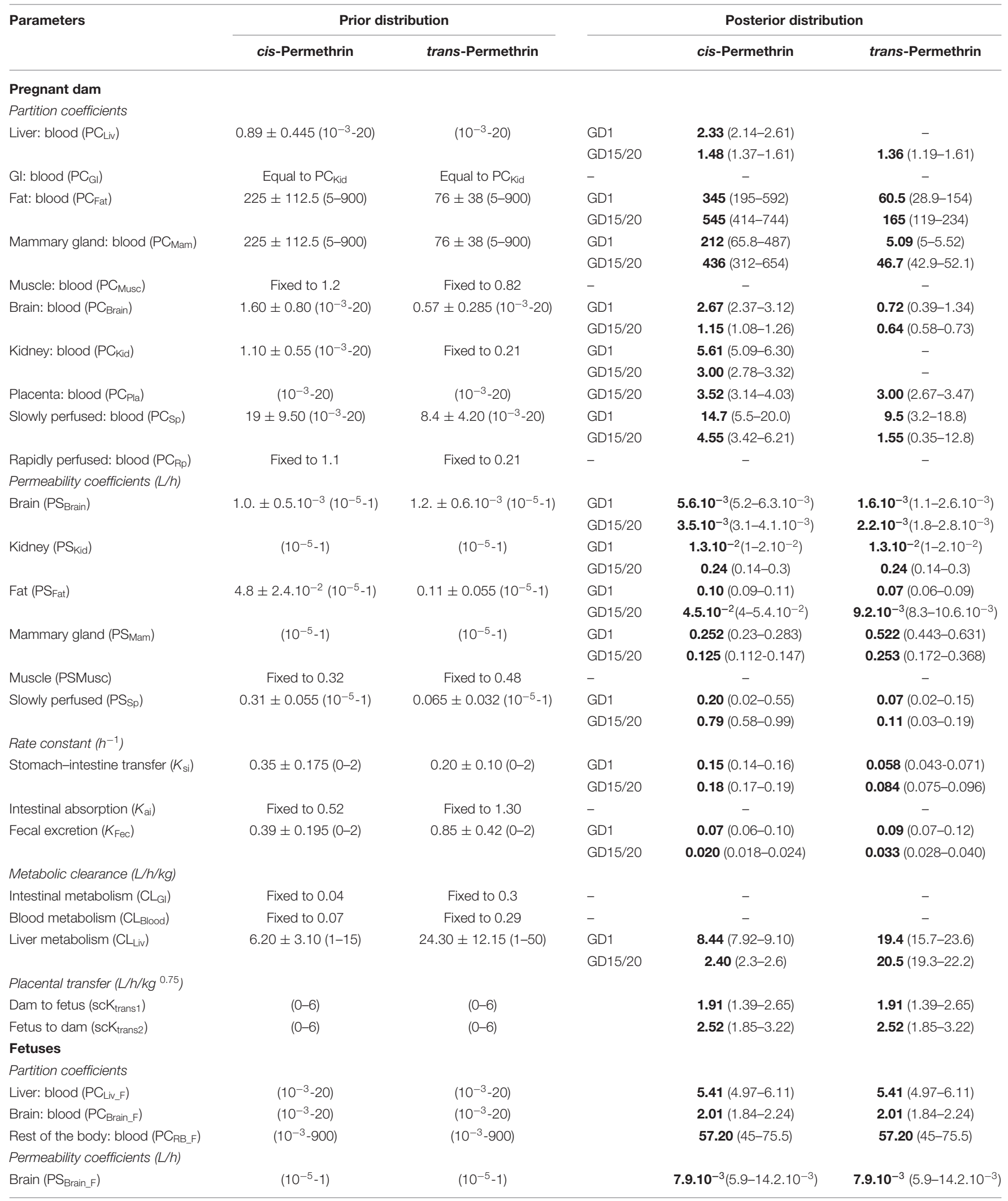

Posterior distributions are represented by mean (value in bold) with the 2.5 th and 97.5 th percentiles. 

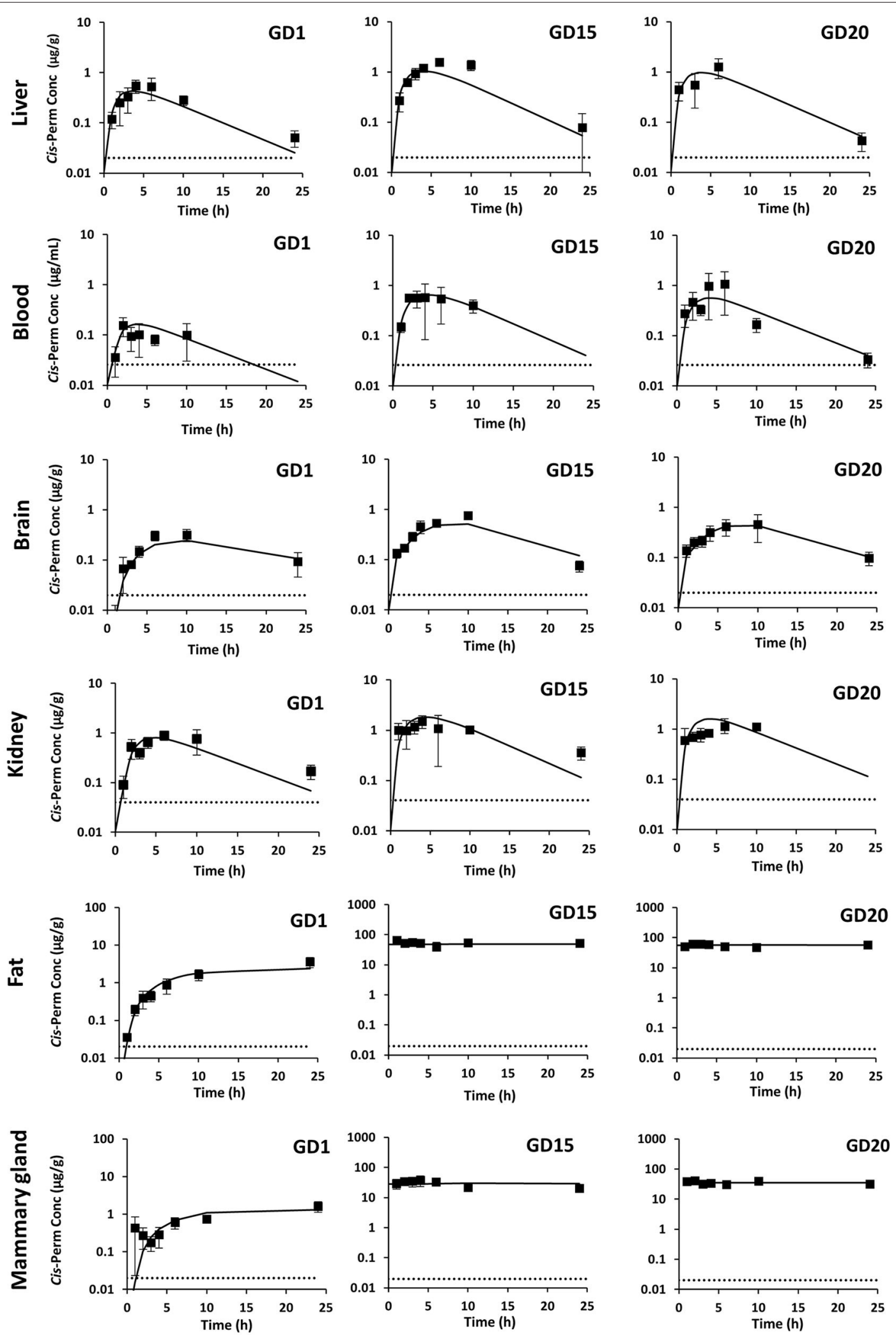

FIGURE 2 | Measured concentrations (squares) and toxicokinetic profiles estimated with the physiologically based pharmacokinetic model (solid line) of cis-permethrin in pregnant rats at GD1, GD15, and GD20. The gray dotted line stands for the limit of quantification. 

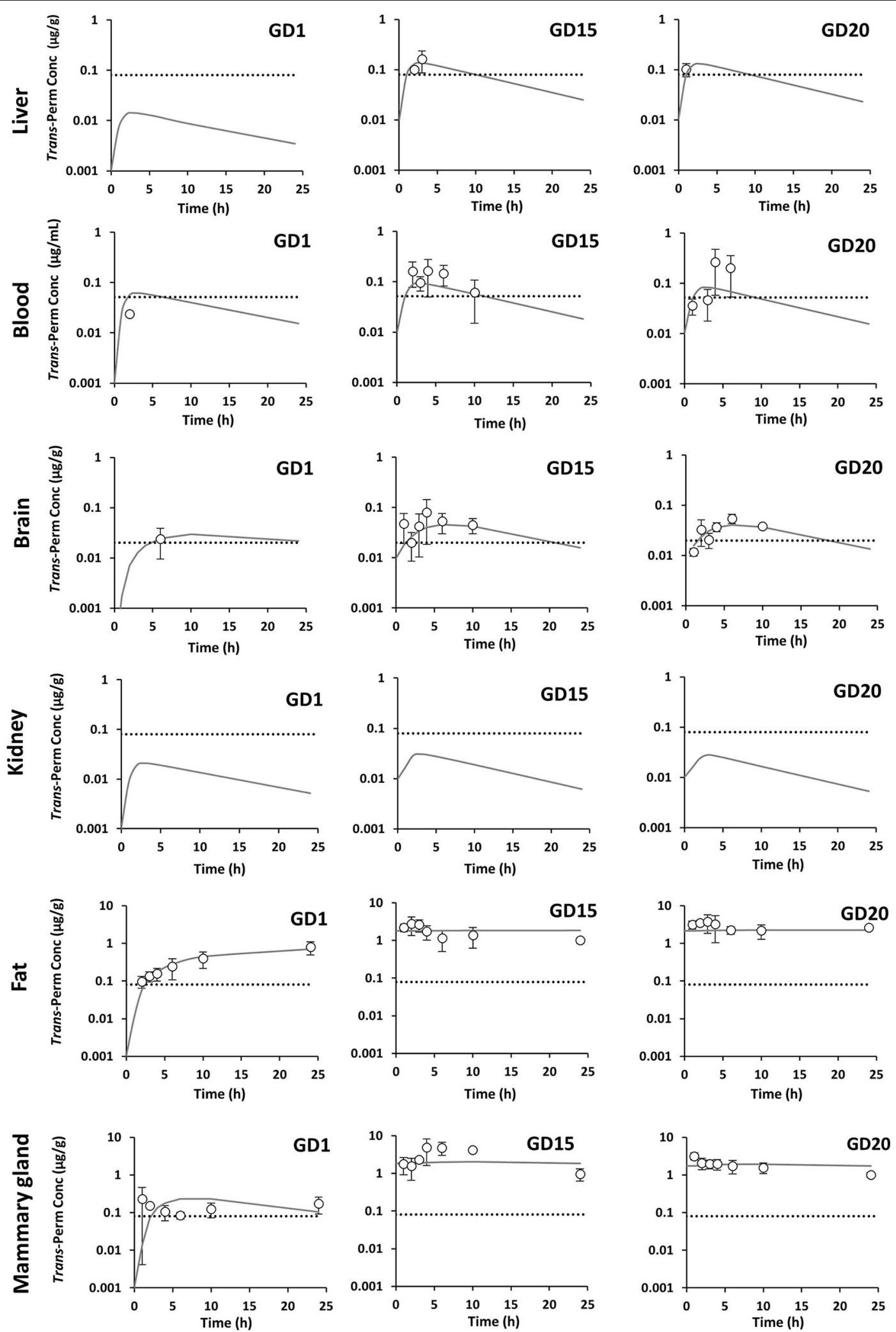

FIGURE 3 | Measured concentrations (dots) and toxicokinetic profiles estimated with the physiologically based pharmacokinetic model (solid line) of trans-permethrin in pregnant rats at GD1, GD15, and GD20. The gray dotted line stands for the limit of quantification. 
repeated administrations until GD15 and GD20. Because transpermethrin is eliminated more rapidly from the body than cis-permethrin, trans-permethrin was not quantified in several samples. Quantification was performed at the three time points studied (GD1, GD15, and GD20) in fat, mammary gland, and feces and only performed at GD15 and GD20 in blood, brain, and liver. Trans-permethrin was not quantified in the kidneys.
For the samples where compounds were detected but below the LOQ, the concentration was set to LOQ/2. The kinetic profiles of cis- and trans-permethrin in blood and tissues at GD1, GD15, and GD20 in pregnant rats are presented in Figures 2, 3, respectively. Cis-permethrin was quantified in placenta, fetal blood, fetal liver, and fetal brain, whereas transpermethrin could only be quantified in placenta and fetal

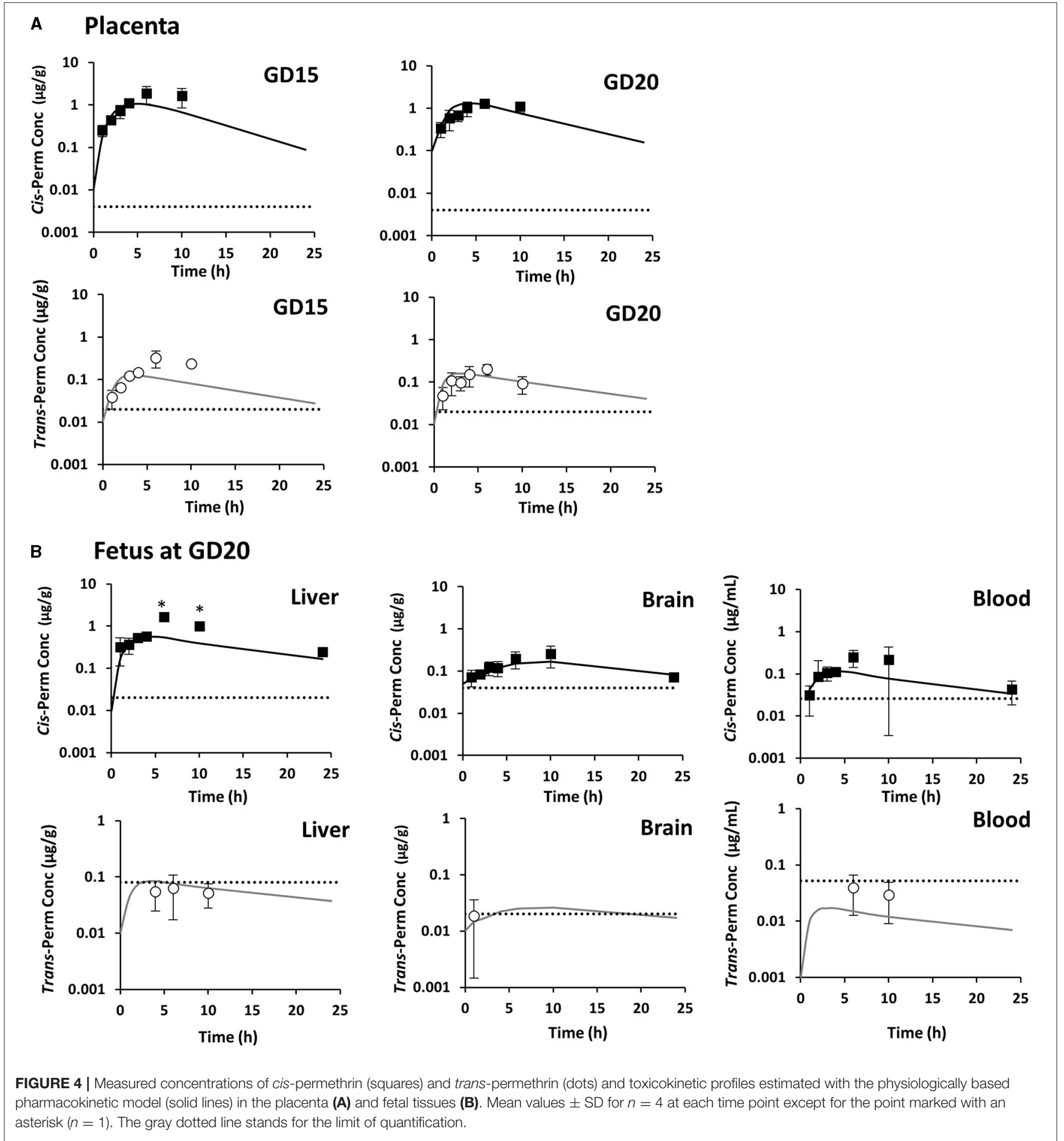


TABLE 3 | Maximum time concentration ( $T_{\max }$, h)/half-lives $\left(T_{1 / 2}, h\right)$ of cis- and trans-permethrin in the blood and tissues of pregnant rats at GD1, GD15, and GD20.

\begin{tabular}{|c|c|c|c|c|c|c|c|c|c|c|c|c|}
\hline & \multicolumn{6}{|c|}{ cis-Permethrin } & \multicolumn{6}{|c|}{ trans-Permethrin } \\
\hline & \multicolumn{2}{|c|}{ GD1 } & \multicolumn{2}{|c|}{ GD15 } & \multicolumn{2}{|c|}{ GD20 } & \multicolumn{2}{|c|}{ GD1 } & \multicolumn{2}{|c|}{ GD15 } & \multicolumn{2}{|c|}{ GD20 } \\
\hline & $\mathbf{T}_{\max }$ & $T_{1 / 2}$ & $\mathbf{T}_{\max }$ & $T_{1 / 2}$ & $\mathbf{T}_{\max }$ & $T_{1 / 2}$ & $\mathbf{T}_{\max }$ & $T_{1 / 2}$ & $T_{\max }$ & $T_{1 / 2}$ & $T_{\max }$ & $T_{1 / 2}$ \\
\hline Blood & 6 & 3.7 & 4 & 2.6 & 6 & 3.6 & - & - & 4 & 3.2 & 4 & $-^{a}$ \\
\hline Liver & 4 & 5.7 & 6 & 3.4 & 6 & 3.7 & - & - & 3 & $-^{\mathrm{a}}$ & - & - \\
\hline Brain & 10 & 7.9 & 10 & 4.2 & 10 & 6.3 & - & - & 4 & 5.4 & 2 & $-^{a}$ \\
\hline Kidney & 6 & 6.5 & 4 & 6.7 & 6 & $-^{\mathrm{a}}$ & - & - & - & - & - & - \\
\hline Fat & 24 & $-^{\mathrm{a}}$ & 1 & $-^{a}$ & 2 & $-^{\mathrm{a}}$ & 10 & $-^{a}$ & 3 & $-^{\mathrm{a}}$ & 3 & $--^{a}$ \\
\hline Mammary gland & 24 & $-^{\mathrm{a}}$ & 4 & $-^{a}$ & 10 & $-^{a}$ & 1 & $-^{a}$ & 4 & $-^{\mathrm{a}}$ & 1 & $--^{a}$ \\
\hline Placenta & na & na & 6 & 3.2 & 6 & 4.5 & na & na & 6 & $-^{a}$ & 6 & $-^{a}$ \\
\hline
\end{tabular}

${ }^{a}$, no half-life was computed due to insufficient data in the elimination phase.

na, not applicable.

- , no compound was quantified.

TABLE 4 | Area under the curve $\left(\mu \mathrm{g} \mathrm{h} / \mathrm{ml}\right.$ or $\mu \mathrm{g} \mathrm{h} / \mathrm{g}$ ) of the observed concentrations ( $\mathrm{AUC}_{\mathrm{obs}}$ ) and the estimated concentrations (AUC $\mathrm{C}_{\text {est }}$ ) for cis-permethrin in the blood and tissues of pregnant rats.

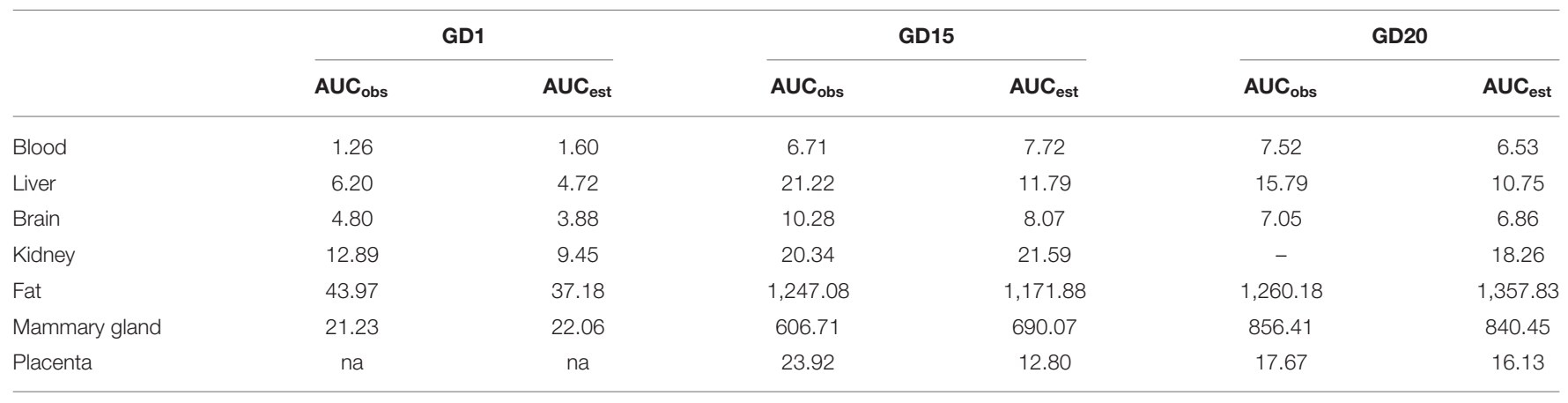

-, no data available.

na, not applicable.

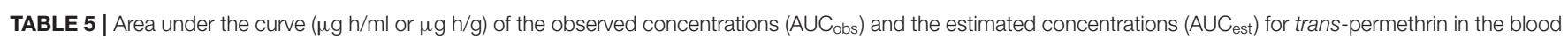
and tissues of pregnant rats.

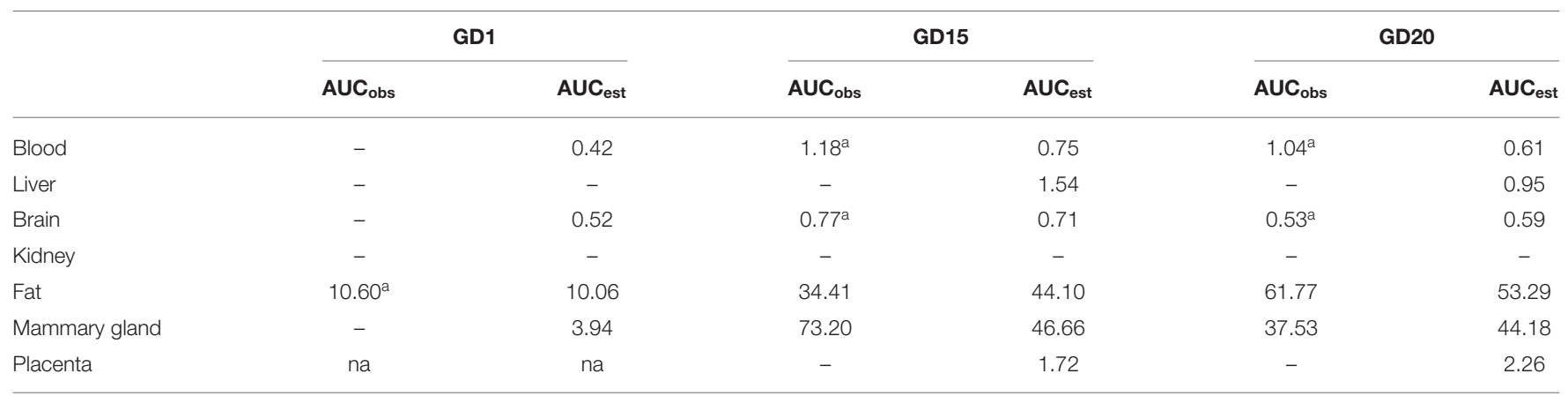

avalue of extrapolated AUC.

na, not applicable.

-, no data available.

brain, even if it could be detected in fetal liver and blood (Figure 4).

For cis-permethrin, after a single administration at GD1, the maximal concentration $\left(C_{\max }\right)$ was reached between 4 and $6 \mathrm{~h}$ in blood, liver, and kidney and declined rapidly, with an observed half-life of 3.7, 5.7, and $6.5 \mathrm{~h}$ (Table 3). In the brain, fat, and mammary gland, a slower diffusion was observed, with the peak concentrations occurring later; at $10 \mathrm{~h}$ in the brain and at $24 \mathrm{~h}$ in fat and mammary gland. In the brain, the estimated half-life was $7.9 \mathrm{~h}$. After repeated administration, there were no significant 
changes in $T_{\max }$ values at GD15 and GD20. However, the values of half-life were reduced compared to GD1, with the lowest values reported at GD15.

In order to compare maternal and fetal exposure, the 24$\mathrm{h}$ area under the curve $\left(\mathrm{AUC}_{\mathrm{obs}}\right)$ for cis-permethrin in blood and tissues was computed using the measured concentrations in pregnant rats and fetuses and are presented in Tables 4, 6, respectively. In pregnant dams, the fat and the mammary gland had the highest $\mathrm{AUC}_{\mathrm{obs}}$, which were respectively 44- and 21fold higher to that in blood at GD1 (Table 4). No significant accumulation was observed after repeated administration in the kidney, liver, and brain, with $\mathrm{AUC}_{\mathrm{obs}}$ ratios between $\mathrm{GD} 1$ and GD15 or GD20 values ranging from 1.5 to 3.4. On the contrary, in blood, fat, and mammary gland, the $\mathrm{AUC}_{\mathrm{obs}}$ values at GD15 and GD20 were increased by 5.3- and 6-fold in blood, 28.4and 28.7-fold in fat, and 28.6- and 40.3-fold in mammary gland compared to GD1. The $\mathrm{AUC}_{\mathrm{obs}}$ in placenta for the cis-isomer was similar at GD15 and GD20 and was 3.6- and 2.3-fold the $\mathrm{AUC}_{\mathrm{obs}}$ in blood, respectively (Table 6). In fetuses, the liver had the highest exposure, and the lowest exposure was observed in blood. The exposure in fetal blood and fetal brain was lower than the exposure of the dam to cis-permethrin. In the brain, the AUC ratio (fetus/dam) was 0.54 . On the contrary, the exposure in the fetal liver was 1.6 times greater than the exposure of the dam in the liver.

Regarding trans-permethrin, the concentrations of the transisomer were always lower than those measured for the cisisomer even if the administration of the trans isomer was slightly higher than the cis-isomer. For the trans-isomer, due to the low number of time points for which the concentration measured was above the LOQ, $\mathrm{AUC}_{\mathrm{obs}}$ could only be estimated in pregnant rats at GD15 and GD20 in blood, brain, and fat and at GD1, GD15, and GD20 in the mammary gland (Table 5). The highest exposures were observed in fat and mammary gland as identified for the cis-isomer and were 29- and 62fold and 59- and 36-fold the $\mathrm{AUC}_{\mathrm{obs}}$ in blood at GD15 and GD20, respectively.

\section{Model Calibration}

\section{Convergence Analysis and Posterior Distributions}

The convergence criterion $\hat{R}$ was computed for the three chains for all parameters calibrated with datasets of GD1 or GD15 and GD20. All the $\hat{R}$ values were below 1.2, indicating that the convergence was reached in both cases. The posterior distributions of the estimated parameters at GD1 or GD15/GD20 are reported in Table 2 as the mean with 95\% confidence interval. The means of the posterior distributions of the estimated parameters at GD1 or GD15/GD20 were compared to prior distribution and between them.

At GD1, the estimated means were close to prior estimates for tissue/blood partition coefficient (PC) in slowly perfused tissue for both isomers and for the hepatic clearance of the trans-isomer only. For the cis-isomer, the hepatic clearance was modestly increased by $36 \%$. For all other parameters, the posterior means differed from their prior values. A decrease was observed for the parameters of absorption $\left(K_{\mathrm{sI}}\right)$ and fecal excretion $\left(K_{\mathrm{Fec}}\right)$, with a decrease of 57 and $72 \%$ for $K_{\text {sI }}$ and 82 and $90 \%$ for
TABLE 6 | Area under the curve ( $\mu \mathrm{g} \mathrm{h/ml} \mathrm{or} \mu \mathrm{g} \mathrm{h} / \mathrm{g}$ ) of the observed concentrations $\left(A \cup C_{o b s}\right)$ and the estimated concentrations $\left(A \cup C_{\text {est }}\right)$ for cis-permethrin in fetal blood, liver, and brain.

\begin{tabular}{lcc}
\hline & \multicolumn{2}{c}{ cis-Permethrin } \\
\cline { 2 - 3 } & AUC $_{\text {obs }}$ & AUC $_{\text {est }}$ \\
\hline Blood & 3.35 & 1.66 \\
Liver & 17.86 & 8.18 \\
Brain & 3.83 & 2.94 \\
\hline
\end{tabular}

$K_{\mathrm{Fec}}$ for cis- and trans-permethrin, respectively. On the contrary, the PC values were markedly increased for cis-permethrin. The mean PC values for the posterior distribution were 1.5-, 2.6-, and 5.1-fold higher than the prior mean values for fat, liver, and kidney.

When compared together, the estimated means at GD15 and GD20 were substantially different from those calibrated with concentration data at GD1, with the exception of $K_{\mathrm{sI}}$ values for both isomers and also hepatic clearance and PC in brain for trans-permethrin. The mean values of all parameters were decreased compared to GD1 values, with the exception of the $\mathrm{PC}$ in fat and mammary gland and permeability coefficients in slowly perfused tissue. For cis-permethrin, the hepatic clearance and fecal excretion were decreased by 3.5- and 3.6fold, respectively. The PCs were decreased by a factor of 1.6, $1.9,2.3$, and 3.2 in the liver, kidney, brain, and slowly perfused tissues, respectively.

In fetuses, the PCs in the brain and liver were highest than their respective values in dams. Asymmetric placental rate constants were observed between maternal placenta and fetal blood, with the majority of the transfer being in the fetal-tomaternal direction. A 0.76 ratio was estimated between transfer rates from the dam to the fetus (scKTrans1) and from the fetus to the dam (scKTrans2).

\section{Comparison of Predictions With Experimental Data}

The experimental data at GD1, GD15, and GD20 were compared with the model predictions with estimated parameters at GD1 or at GD15 and GD20 (Figures 2-4). The estimated concentrations were generally in good agreement with the observed data in blood and tissues in dams. The estimated and observed AUC in pregnant rats and fetuses are reported in Tables 46. The estimated to observed AUC ratios for cis- and transpermethrin were within a range between 0.5 and 1.5 , indicating acceptable prediction results with the exception of fetal liver. For fetal liver, the AUC ratio was 0.46. However, at time points $+6 \mathrm{~h}$ and $+10 \mathrm{~h}$, cis-permethrin was only quantifiable in one sample.

Using the model, it was possible to estimate AUC for trans-permethrin in pregnant rats notably after a single administration at GD1 even if the lack of measured concentrations prevents the computation of an observed $\mathrm{AUC}_{\mathrm{obs}}$ (Table 5). At GD1, the tissue/blood ratios for $\mathrm{AUC}_{\mathrm{est}}$ were 1.2 in the brain and 9.4 and 24 in mammary gland and fat, respectively. In fat and mammary gland, these 
ratios were $\sim 2$-fold lower than those observed with cispermethrin, similar to the observed ratio in fat in toxicokinetic studies performed in male rats with permethrin (cis/trans, 40:60) (40).

Based on $\mathrm{AUC}_{\mathrm{est}}$, the AUC values for the cis-isomer were 3.7to 5.6-fold greater than that of the trans-isomer in blood and tissues at GD1. At GD15 and GD20, the cis/trans $\mathrm{AUC}_{\text {est }}$ ratios were increased compared to those calculated at GD1.

\section{Sensitivity Analyses}

The GSA identified the parameters to which the maternal and fetal blood concentrations and fetal brain concentrations are sensitive at GD15 and GD20. Three parameters mostly influenced the maternal blood concentration at the three time points (4, 6, and $12 \mathrm{~h}$ after the oral administration), i.e., the hepatic clearance and absorption parameters, partition coefficient (Supplementary Figure S1). The influence of the other model parameters is quite negligible. Regarding the fetal dosimetry in blood and brain, the hepatic clearance is still the most influential parameter (Supplementary Figures S2, S3). The absorption parameters also have an impact on the blood concentration, with a decreasing influence over time. As it could have been expected, the fetal blood and brain concentrations are sensitive to the two parameters driving the placental transfer ( $K_{\text {trans } 1}$ and $\left.K_{\text {trans } 2}\right)$. Due to its high volume, the compartment "rest of the body" also influences the kinetics in fetal blood. In the brain, the partitioning in the tissues $\left(P C_{B r a i n F}\right)$ and the permeability $\left(P S_{B r a i n F}\right)$ become influential parameters. For all model outputs, the rankings of the parameters by the first order and total order indices were similar, and significant interactions were observed between the most influential parameters.

\section{DISCUSSION}

Gestation induces numerous physiological, biochemical, and metabolic changes that can affect the disposition of xenobiotics (61). Assessing the fetal exposure during the whole gestation will then require careful considerations of the maternal exposure. In this paper, we extended the structure of a PBPK model for permethrin in adult male rats $(38,40)$ to integrate the dynamic changes occurring during gestation. Published toxicokinetic data for permethrin isomers were obtained in male rats after a single-dose administration $(38,40,62)$. The existence of gender differences in kinetics of pyrethroids has not been experimentally studied for the parent compounds but only for some metabolites, 3-phenoxybenzyl alcohol and 3phenoxybenzaldehyde, in rats for which gender differences were observed (63). To characterize these potential differences for permethrin, we collected toxicokinetic data after a single oral dose at the first day of gestation (GD1), as the modifications due to gestation are supposed to be negligible at GD1.

Compared to the known toxicokinetic profile of permethrin in male rats, female rats demonstrated a similar hepatic clearance but with a slower absorption rate. Indeed the estimated stomach intestine rate transfers $\left(K_{\mathrm{si}}\right)$ in females were 2.3- and 3.6fold lower compared to those in males for cis- and transpermethrin, respectively. These results are in accordance with the sex differences in the gastrointestinal tract that have been reported in rats (64) and the higher gastric mucosal blood flow observed in male than in female rats (65).

Cis- and trans-permethrin were mainly distributed in tissues, with a high accumulation in fat and mammary glands. The estimated AUCs for cis- and trans-permethrin in blood (normalized by the dose) were similar to those reported by Tornero et al. (40) at $10 \mathrm{mg} / \mathrm{kg}$ but 2.7 and 5.7 lower than those reported in Willemin et al. (38) at $25 \mathrm{mg} / \mathrm{kg}$ for each isomer, respectively. However, in the study of Willemin et al., the blood concentrations exceeded the binding capacity of rat plasma, impacting the estimation of partition coefficients (66). In our study, the observed $C_{\max }$ in blood for cis-permethrin was $260 \mathrm{nM}$, in the linear range of the binding in plasma. Highest tissue/blood partitions coefficients were estimated in our study compared to those reported for males in the study of Tornero et al. (40). In rats, cis- and trans-permethrin are primarily bound by plasma proteins (50-60\%) and, to a lesser amount, by lipoproteins (30$35 \%)(67)$. Sex differences in plasma apolipoprotein profiles have been reported in rats, with higher concentrations observed in males than in females (68), which could explain these differences observed between the studies.

Using estimated parameters at GD1, corresponding to a nonpregnant rat, the model was not able to capture the toxicokinetic at GD15 and GD20, demonstrating an impact of gestation on the toxicokinetic profile of permethrin. The main observed differences were related to hepatic clearance and tissue/blood PC. The predicted hepatic clearance of cis-permethrin at GD15 and GD20 was reduced by 3.5 compared to the prediction at GD1.

The calibration was performed in a Bayesian interference framework, allowing the integration of informative prior knowledge on the parameters and experimental data to optimize the model parameter values and inform on their variability. The sensitivity analysis identified hepatic clearance, absorption parameters, and partition coefficients as having the most impact on blood and brain concentrations. These results were in agreement with previously published sensitivity analyses on the kinetics of permethrin and deltamethrin in rodents or humans $(41,42,58)$. Because the model was not able to capture the kinetics observed at GD1, GD15, and GD20 with the same set of parameter values, the model was calibrated independently with the data generated at GD1 after a single-dose administration and the data generated at GD15 or GD20 after repeated daily yielding to two different sets of parameters for GD1 and GD15/GD20. The main differences between these two sets of estimated values were related to the hepatic clearance and the tissue/blood partition coefficients. The predicted hepatic clearance of cis-permethrin at GD15 and GD20 was reduced by a 3.5 factor compared to the value estimated at GD1.

Gestation is associated with a small decrease in total rodent liver P450 content and/or activity $(69,70)$, which can explain these differences in the metabolic rate of the cis-isomer. For transpermethrin, it was not possible to observe such a reduction due to the limited number of time points at which the isomer was quantified. The respective values of the PCs for fat and mammary gland were markedly increased by 1.6 and 2.1 for cis-permethrin and 2.7 and 9.2 for trans-permethrin. This evolution might be 
explained by the fact that blood lipid levels can increase up to 4fold during gestation (71) and affect the disposition of lipophilic compounds such as permethrin $[\log P=6.1$; (40)]. Moreover, maternal fat content progressively increases during gestation and mammary fat accumulation increases intensely from day 12 of gestation, contributing to maternal fat storage $(48,72)$. These differences in blood and tissue composition during the gestation may explain the changes in PC values and the changes in pharmacokinetic profile after chronic administration during the whole gestation, with a marked accumulation in fat tissues and mammary glands.

The other main objective of our PBPK model in rat was to predict the internal dose in the fetal brain to help in risk assessment. PBPK models allow inter-species extrapolations (73) and can be used to estimate human fetal exposure in inaccessible compartments such as the brain (74). The estimated concentrations in the fetal brain could aid in the selection of appropriate doses to investigate the neurodevelopmental toxicity using human in vitro systems. To assess exposure in the fetal brain and to facilitate its use in a risk assessment context, a compartmental structure was established for the fetal PBPK model, with mass communication via the bloodplacenta barrier. Using estimated parameters in pregnant rats and fetuses, the model was able to reproduce correctly the kinetics of both cis- and trans-isomers in fetal blood and tissues even if trans-permethrin was only quantifiable in fetal brain due to analytical limitations. The fetal brain was exposed to permethrin, demonstrating that exposure during pregnancy is of concern for the developing brain even if fetal exposure was less than maternal exposure with a feto/maternal (FM) ratio of 0.54 . In blood, the FM ratio was 0.25 for cispermethrin, which is close to the FM ratio of 0.5 reported for cypermethrin, another pyrethroid in placental perfusion studies in humans (75). In our model, transfers from the placenta to the fetuses were considered as a simple diffusion with an estimated placental rate constant value from the dam to the fetuses of $1.91 \mathrm{~L} / \mathrm{h} / \mathrm{kg}^{0.75}$. This value was close to that reported for other pesticides, such as atrazine in rats (76). However, the placental transfer of permethrin could also involve active transports, and further data are needed to characterize placental transfer.

In conclusion, we developed a gestation PBPK model in rats, allowing the identification of key parameters affecting maternal exposure to cis- and trans-permethrin during gestation and an accurate prediction of fetal brain tissue distribution in rats. In rodents, permethrin and other pyrethroids have shown neurodevelopmental effects. The interpretation of animal studies is challenging due to the lack of assessment of the internal exposure and variable exposure periods and doses

\section{REFERENCES}

1. Saillenfait A-M, Ndiaye D, Sabaté J-P. Pyrethroids: exposure and health effects - an update. Int J Hyg Environ Health. (2015) 218:281-92. doi: 10.1016/j.ijheh.2015. 01.002 used. This model could be used to predict brain levels in reported studies in animals during gestational exposure to aid in risk assessment. Moreover, the mechanisms by which chronic early-life permethrin and pyrethroids could exert developmental neurotoxicity was not well-understood (77). The model allows the estimation of relevant concentrations in the fetal brain in rats. The model could be extrapolated to humans by including specific human values for parameters required for the PBPK model and relevant in vitro data for clearance-specific parameters (78). The human pregnancy PBPK model could then be used to estimate relevant concentrations in the fetal brain to test in in vitro systems. Once more data will be available, these data could be integrated in specific adverse outcome pathways to assess developmental neurotoxicity in humans.

\section{DATA AVAILABILITY STATEMENT}

The raw data supporting the conclusions of this article will be made available by the authors, without undue reservation.

\section{ETHICS STATEMENT}

The animal study was reviewed and approved by a regional Ethic Committee on experiments using animals (CREMEAP no.96) and the French Ministry of Research with the permit number 01812.01 .

\section{AUTHOR CONTRIBUTIONS}

SP and FZ formulated the research questions and designed the studies. SD, FR, and AL performed the experimental study in rats. SP, PM, and AC performed the chemical analysis. SP, FZ, and CB performed the PBPK modeling. $\mathrm{CB}$ ran the sensitivity analyses. SP wrote the manuscript. FZ and $\mathrm{CB}$ provided critical review and comments. FZ and VB were the supervisors of this research. All authors contributed to the article and approved the submitted version.

\section{FUNDING}

This work was supported by the French Ministry of Ecology and Sustainable Development (Program 190) and by the HBM4EU project.

\section{SUPPLEMENTARY MATERIAL}

The Supplementary Material for this article can be found online at: https://www.frontiersin.org/articles/10.3389/fped. 2021.730383/full\#supplementary-material

2. Feo ML, Eljarrat E, Barceló D, Barceló D. Determination of pyrethroid insecticides in environmental samples. TrAC Trends Anal Chem. (2010) 29:692-705. doi: 10.1016/j.trac.2010.03.011

3. Weston DP, Holmes RW, You J, Lydy MJ. Aquatic toxicity due to residential use of pyrethroid insecticides. Environ Sci Technol. (2005) 39:9778-84. doi: 10.1021/es0506354 
4. Heudorf U, Angerer J. Metabolites of pyrethroid insecticides in urine specimens: current exposure in an urban population in Germany. Environ Health Perspect. (2001) 109:213. doi: 10.1289/ehp.01109213

5. Dereumeaux C, Saoudi A, Pecheux M, Berat B, de Crouy-Chanel P, Zaros C, et al. Biomarkers of exposure to environmental contaminants in French pregnant women from the Elfe cohort in 2011. Environ Int. (2016) 97:56-67. doi: 10.1016/j.envint.2016.10.013

6. Castorina R, Bradman A, Fenster L, Barr DB, Bravo R, Vedar MG, et al. Comparison of current-use pesticide and other toxicant urinary metabolite levels among pregnant women in the CHAMACOS cohort and NHANES. Environ Health Perspect. (2010) 118:856-63. doi: 10.1289/ehp.09 01568

7. Dewailly E, Forde M, Robertson L, Kaddar N, Laouan Sidi EA, Côté S, et al. Evaluation of pyrethroid exposures in pregnant women from 10 Caribbean countries. Environ Int. (2014) 63:201-6. doi: 10.1016/j.envint.2013.11.014

8. Lewis RC, Cantonwine DE, Anzalota Del Toro LV, Calafat AM, ValentinBlasini L, et al. Urinary biomarkers of exposure to insecticides, herbicides, and one insect repellent among pregnant women in Puerto Rico. Environ Health. (2014) 13:97. doi: 10.1186/1476-069X-13-97

9. Watkins DJ, Fortenberry GZ, Sánchez BN, Barr DB, Panuwet P, Schnaas L, et al. Urinary 3-phenoxybenzoic acid (3-PBA) levels among pregnant women in Mexico City: Distribution and relationships with child neurodevelopment. Environ Res. (2016) 147:307-13. doi: 10.1016/j.envres.2016.02.025

10. Woodruff TJ, Zota AR, Schwartz JM. Environmental chemicals in pregnant women in the United States: NHANES 2003-2004. Environ Health Perspect. (2011) 119:878-85. doi: 10.1289/ehp.1002727

11. Zhang J, Hisada A, Yoshinaga J, Shiraishi H, Shimodaira K, Okai T, et al. Exposure to pyrethroids insecticides and serum levels of thyroidrelated measures in pregnant women. Environ Res. (2013) 127:16-21. doi: 10.1016/j.envres.2013.10.001

12. Dereumeaux C, Saoudi A, Goria S, Wagner V, De Crouy-Chanel P, Pecheux $\mathrm{M}$, et al. Urinary levels of pyrethroid pesticides and determinants in pregnant French women from the Elfe cohort. Environ Int. (2018) 119:89-99. doi: 10.1016/j.envint.2018.04.042

13. Neta G, Goldman LR, Barr D, Apelberg BJ, Witter FR, Halden RU. Fetal exposure to chlordane and permethrin mixtures in relation to inflammatory cytokines and birth outcomes. Environ Sci Technol. (2011) 45:1680-7. doi: 10.1021/es103417j

14. Pérez JJ, Williams MK, Weerasekera G, Smith K, Whyatt RM, Needham LL, et al. Measurement of pyrethroid, organophosphorus, and carbamate insecticides in human plasma using isotope dilution gas chromatographyhigh resolution mass spectrometry. J Chromatogr B. (2010) 878:2554-62. doi: 10.1016/j.jchromb.2010.03.015

15. Berton T, Mayhoub F, Chardon K, Duca R-C, Lestremau F, Bach V, et al. Development of an analytical strategy based on LC-MS/MS for the measurement of different classes of pesticides and theirs metabolites in meconium: application and characterisation of foetal exposure in France. Environ Res. (2014) 132:311-20. doi: 10.1016/j.envres.2014.03.034

16. Meyer-Monath M, Chatellier C, Cabooter D, Rouget F, Morel I, Lestremau F. Development of liquid chromatography methods coupled to mass spectrometry for the analysis of substances with a wide variety of polarity in meconium. Talanta. (2015) 138:231-9. doi: 10.1016/j.talanta.2015.02.058

17. Cassoulet R, Haroune L, Abdelouahab N, Gillet V, Baccarelli AA, Cabana H, et al. Monitoring of prenatal exposure to organic and inorganic contaminants using meconium from an Eastern Canada cohort. Environ Res. (2019) 171:4451. doi: 10.1016/j.envres.2018.12.044

18. Tran NQV, Miyake K. Neurodevelopmental disorders and environmental toxicants: epigenetics as an underlying mechanism. Int J Genomics. (2017) 2017:1-23. doi: 10.1155/2017/7526592

19. Rodier PM. Developing brain as a target of toxicity. Environ Health Perspect. (1995) 103(Suppl. 6):73-6.

20. Shafer TJ, Meyer DA, Crofton KM. developmental neurotoxicity of pyrethroid insecticides: critical review and future research needs. Environ Health Perspect. (2004) 113:123-36. doi: 10.1289/ehp.7254

21. Viel J-F, Warembourg C, Le Maner-Idrissi G, Lacroix A, Limon G, Rouget F, et al. Pyrethroid insecticide exposure and cognitive developmental disabilities in children: the PELAGIE mother-child cohort. Environ Int. (2015) 82:69-75. doi: 10.1016/j.envint.2015.05.009
22. Viel J-F, Rouget F, Warembourg C, Monfort C, Limon G, Cordier S, et al. Behavioural disorders in 6-year-old children and pyrethroid insecticide exposure: the PELAGIE mother-child cohort. Occup Env Med. (2017) 74:27581. doi: 10.1136/oemed-2016-104035

23. Shelton JF, Geraghty EM, Tancredi DJ, Delwiche LD, Schmidt RJ, Ritz B, et al. Neurodevelopmental disorders and prenatal residential proximity to agricultural pesticides: The CHARGE study. Environ Health Perspect. (2014) 122:1103-9. doi: 10.1289/ehp.13 07044

24. Horton MK, Rundle A, Camann DE, Boyd Barr D, Rauh VA, Whyatt RM. Impact of prenatal exposure to piperonyl butoxide and permethrin on 36-month neurodevelopment. Pediatrics. (2011) 127:e699-706. doi: 10.1542/peds.2010-0133

25. Ostrea EM, Bielawski DM, Posecion NC, Corrion M, Villanueva-Uy E, Bernardo RC, et al. Combined analysis of prenatal (maternal hair and blood) and neonatal (infant hair, cord blood and meconium) matrices to detect fetal exposure to environmental pesticides. Environ Res. (2009) 109:116-22. doi: 10.1016/j.envres.2008.09.004

26. von Ehrenstein OS, Ling C, Cui X, Cockburn M, Park AS, Yu F, et al. Prenatal and infant exposure to ambient pesticides and autism spectrum disorder in children: population based case-control study. BMJ. (2019) 364:1962. doi: 10.1136/bmj.1962

27. Dalsager L, Fage-Larsen B, Bilenberg N, Jensen TK, Nielsen F, Kyhl HB, et al. Maternal urinary concentrations of pyrethroid and chlorpyrifos metabolites and attention deficit hyperactivity disorder (ADHD) symptoms in 2-4-yearold children from the Odense Child Cohort. Environ Res. (2019) 176:108533. doi: 10.1016/j.envres.2019.108533

28. Barkoski JM, Philippat C, Tancredi D, Schmidt RJ, Ozonoff S, Barr $\mathrm{DB}$, et al. In utero pyrethroid pesticide exposure in relation to autism spectrum disorder (ASD) and other neurodevelopmental outcomes at 3 years in the MARBLES longitudinal cohort. Environ Res. (2021) 194:110495. doi: 10.1016/j.envres.2020. 110495

29. Ueyama J, Saito I, Kamijima M. Analysis and evaluation of pyrethroid exposure in human population based on biological monitoring of urinary pyrethroid metabolites. J Pestic Sci. (2010) 35:87-98. doi: 10.1584/jpestics.R10-01

30. Darney K, Bodin L, Bouchard M, Côté J, Volatier J-L, Desvignes V. Aggregate exposure of the adult French population to pyrethroids. Toxicol Appl Pharmacol. (2018) 351:21-31. doi: 10.1016/j.taap.2018. 05.007

31. US EPA. Pesticides : Industry Sales and Usage : 2006 and 2007 Market Estimate (2007).

32. Carloni M, Nasuti C, Fedeli D, Montani M, Amici A, Vadhana MSD, et al. The impact of early life permethrin exposure on development of neurodegeneration in adulthood. Exp Gerontol. (2012) Washington, 47:60-6. doi: 10.1016/j.exger.2011.10.006

33. Carloni M, Nasuti C, Fedeli D, Montani M, Vadhana MSD, Amici A, et al. Early life permethrin exposure induces long-term brain changes in Nurr1, NF-kB and Nrf-2. Brain Res. (2013) 1515:19-28. doi: 10.1016/j.brainres.2013.03.048

34. Imanishi $\mathrm{S}$, Okura $\mathrm{M}$, Zaha $\mathrm{H}$, Yamamoto $\mathrm{T}$, Akanuma $\mathrm{H}$, Nagano $\mathrm{R}$, et al. Prenatal exposure to permethrin influences vascular development of fetal brain and adult behavior in mice offspring: prenatal Exposure to Permethrin Influences Brain in Offspring. Environ Toxicol. (2013) 28:617-29. doi: 10.1002/tox. 20758

35. Nasuti C, Carloni M, Fedeli D, Gabbianelli R, Di Stefano A, Laura Serafina C, et al. Effects of early life permethrin exposure on spatial working memory and on monoamine levels in different brain areas of pre-senescent rats. Toxicology. (2013) 303:162-8. doi: 10.1016/j.tox.2012. 09.016

36. Saito H, Hara K, Tominaga T, Nakashima K, Tanemura K. Early-life exposure to low levels of permethrin exerts impairments in learning and memory with the effects on neuronal and glial population in adult male mice. J Appl Toxicol. (2019) 39:1651-62. doi: 10.1002/jat.3882

37. US EPA. Approaches for the Application of Physiologically Based Pharmacokinetic (PBPK) Models and Supporting Data in Risk Assessment (2006) Washington. 
38. Willemin M-E, Desmots S, Le Grand R, Lestremau F, Zeman FA, Leclerc E, et al. PBPK modeling of the cis- and trans-permethrin isomers and their major urinary metabolites in rats. Toxicol Appl Pharmacol. (2016) 294:65-77. doi: 10.1016/j.taap.2016.01.011

39. Song G, Moreau M, Efremenko A, Lake BG, Wu H, Bruckner JV, et al. Evaluation of age-related pyrethroid pharmacokinetic differences in rats: physiologically-based pharmacokinetic model development using in vitro data and in vitro to in vivo extrapolation. Toxicol Sci. (2019) 169:365-79. doi: $10.1093 /$ toxsci/kfz042

40. Tornero-Velez R, Davis J, Scollon EJ, Starr JM, Setzer RW, Goldsmith M$\mathrm{R}$, et al. A pharmacokinetic model of cis- and trans-permethrin disposition in rats and humans with aggregate exposure application. Toxicol Sci. (2012) 130:33-47. doi: 10.1093/toxsci/kfs236

41. Wei B, Isukapalli SS, Weisel CP. Studying permethrin exposure in flight attendants using a physiologically based pharmacokinetic model. J Expo Sci Environ Epidemiol. (2013) 23:416-27. doi: 10.1038/jes. 2013.12

42. Quindroit P, Beaudouin R, Brochot C. Estimating the cumulative human exposures to pyrethroids by combined multi-route PBPK models: application to the French population. Toxicol Lett. (2019) 312:125-38. doi: 10.1016/j.toxlet.2019.05.007

43. Mallick P, Moreau M, Song G, Efremenko AY, Pendse SN, Creek MR, et al. Development and application of a life-stage Physiologically Based Pharmacokinetic (PBPK) model to the assessment of internal dose of pyrethroids in humans. Toxicol Sci. (2020) 173:86-99. doi: 10.1093/toxsci/kfz211

44. Personne S, Marcelo P, Pilard S, Baltora-Rosset S, Corona A, Robidel F, et al. Determination of maternal and foetal distribution of cisand trans-permethrin isomers and their metabolites in pregnant rats by liquid chromatography tandem mass spectrometry (LC-MS/MS). Anal Bioanal Chem. (2019) 411:8043-52. doi: 10.1007/s00216-019-0 2157-7

45. Dowell T, Kauer CD. Maternal hemodynamics and uteroplacental blood flow throughout gestation in conscious rats. Methods Find Exp Clin Pharmacol. (1997) 19:613-25.

46. Brown RP, Delp MD, Lindstedt SL, Rhomberg LR, Beliles RP. Physiological parameter values for physiologically based pharmacokinetic models. Toxicol Ind Health. (1997) 13:407-84. doi: 10.1177/074823379701300401

47. Hanwell A, Linzell JL. The time course of cardiovascular changes in lactation in the rat. J Physiol. (1973) 233:93-109. doi: 10.1113/jphysiol.1973.sp010299

48. Rosso P, Keyou G, Bassi JA, Slusser WM. Effect of malnutrition during pregnancy on the development of the mammary glands of rats. J Nutr. (1981) 111:1937-41. doi: 10.1093/jn/111.11.1937

49. Naismith DJ, Richardson DP, Pritchard AE. The utilization of protein and energy during lactation in the rat, with particular regard to the use of fat accumulated in pregnancy. Br J Nutr. (1982) 48:433. doi: 10.1079/BJN19820125

50. Clewell RA. Predicting fetal perchlorate dose and inhibition of iodide kinetics during gestation: a physiologically-based pharmacokinetic analysis of perchlorate and iodide kinetics in the rat. Toxicol Sci. (2003) 73:235-55. doi: 10.1093/toxsci/kfg081

51. O'Flaherty EJ, Scott W, Schreiner C, Beliles RP. A physiologically based kinetic model of rat and mouse gestation: disposition of a weak acid. Toxicol Appl Pharmacol. (1992) 112:245-56. doi: 10.1016/0041-008X(92)90194-W

52. Yoon M, Nong A, Clewell HJ, Taylor MD, Dorman DC, Andersen ME. Evaluating placental transfer and tissue concentrations of manganese in the pregnant rat and fetuses after inhalation exposures with a PBPK model. Toxicol Sci. (2009) 112:44-58. doi: 10.1093/toxsci/kfp198

53. Sikov MR, Thomas JM. Prenatal growth of the rat. Growth. (1970) 34:1-14.

54. Girard H, Klappstein S, Bartag, I, Moll, W. Blood circulation and oxygen transport in the fetal guinea pig. J Dev Physiol. (1983) 5:181-93.

55. Carter, AM, Gu W. Cerebral blood fow in the fetal guinea pig. J Dev Physiol. (1988) 10:123-9. doi: 10.1016/0143-4004(89)90089-1

56. Itskovitz J, LaGamma EF, Rudolph AM. Effects of cord compression on fetal blood flow distribution and O2 delivery. Am J Physiol Heart Circ Physiol. (1987) 252:H100-9. doi: 10.1152/ajpheart.1987.252.1.H100

57. Gelman A, Meng X-L, Stern H. Posterior predictive assessment of model fitness via realized discrepancies. Stat Sin. (1996) 6:733-807.
58. Godin SJ, DeVito MJ, Hughes MF, Ross DG, Scollon EJ, Starr JM, et al. Physiologically based pharmacokinetic modeling of deltamethrin: development of a rat and human diffusion-limited model. Toxicol Sci. (2010) 115:330-43. doi: 10.1093/toxsci/kfq051

59. Crow J, Borazjani A, Potter P, Ross M. Hydrolysis of pyrethroids by human and rat tissues: examination of intestinal, liver and serum carboxylesterases. Toxicol Appl Pharmacol. (2007) 221:1-12. doi: 10.1016/j.taap.2007.03.002

60. Gelman A, Bois F, Jiang J. Physiological pharmacokinetic analysis using population modeling and informative prior distributions. J Am Stat Assoc. (1996) 91:1400-12. doi: 10.1080/01621459.1996.104 76708

61. Lu G, Abduljalil K, Jamei M, Johnson TN, Soltani H, Rostami-Hodjegan. Physiologically-based Pharmacokinetic (PBPK) models for assessing the kinerics of xenobiotics during pregnancy: achievements and shortcomings. Curr Drug Metab. (2012) 13:695-720. doi: 10.2174/138920012800840374

62. Anadon A, Martinez-Larranaga MR, Diaz MJ, Bringas P. Toxicokinetics of permethrin in the rat. Toxicol Appl Pharmacol. (1991) 110:1-8. doi: 10.1016/0041-008X(91)90284-L

63. Ueyama J, Hirosawa N, Mochizuki A, Kimata A, Kamijima M, Kondo T, et al. Toxicokinetics of pyrethroid metabolites in male and female rats. Environ Toxicol Pharmacol. (2010) 30:88-91. doi: 10.1016/j.etap.2010.03.017

64. Afonso-Pereira F, Dou L, Trenfield SJ, Madla CM, Murdan S, Sousa J, et al. Sex differences in the gastrointestinal tract of rats and the implications for oral drug delivery. Eur J Pharm Sci. (2018) 115:339-44. doi: 10.1016/j.ejps.2018.01.043

65. Shore R, Björne H, Omoto Y, Siemiatkowska A, Gustafsson J-Å, Lindblad M, et al. Sex differences and effects of oestrogen in rat gastric mucosal defence. World J Gastroenterol. (2017) 23:426. doi: 10.3748/wjg.v23.i3.426

66. Sethi P, Bruckner JV, Mortuza TB, Cummings BS, Muralidhara S, White CA. Plasma protein and lipoprotein binding of Cis - and Trans -permethrin and deltamethrin in adult humans and rats. Drug Metab Dispos. (2019) 47:941-8. doi: 10.1124/dmd.118.085464

67. Sethi PK, Muralidhara S, Bruckner JV, White CA. Measurement of plasma protein and lipoprotein binding of pyrethroids. J Pharmacol Toxicol Methods. (2014) 70:106-11. doi: 10.1016/j.vascn.2014.06.002

68. Van Lenten BJ, Jenkins CH, Roheim PS. Plasma apolipoprotein profiles of male and female rats. Atherosclerosis. (1980) 37:569-77. doi: 10.1016/0021-9150(80)90064-7

69. He XJ, Ejiri N, Nakayama H, Doi K. Effects of pregnancy on CYPs protein expression in rat liver. Exp Mol Pathol. (2005) 78:64-70. doi: 10.1016/j.yexmp.2004.08.011

70. He XJ, Yamauchi H, Suzuki K, Ueno M, Nakayama H, Doi K. Gene expression profiles of drug-metabolizing enzymes (DMEs) in rat liver during pregnancy and lactation. Exp Mol Pathol. (2007) 83:428-34. doi: 10.1016/j.yexmp.2006.05.002

71. McMullin TS, Lowe ER, Bartels MJ, Marty MS. Dynamic changes in lipids and proteins of maternal, fetal, and pup blood and milk during perinatal development in CD and wistar rats. Toxicol Sci. (2008) 105:260-74. doi: $10.1093 /$ toxsci/kfn124

72. López-Luna P, Maier I, Herrera E. Carcass and tissue fat content in the pregnant rat. Neonatology. (1991) 60:29-38. doi: 10.1159/000243385

73. Andersen ME. Development of physiologically based pharmacokinetic and physiologically based pharmacodymamic models for applications in toxicology and risk assessment. Decis Subtances Methodol Hum Health Risk Assess Toxic Subst. (1995) 79:35-44. doi: 10.1016/0378-4274(95)03355-O

74. Sager JE, Yu J, Ragueneau-Majlessi I, Isoherranen N. Physiologically Based Pharmacokinetic (PBPK) modeling and simulation approaches: a systematic review of published models, applications, and model verification. Drug Metab Dispos. (2015) 43:1823-37. doi: 10.1124/dmd.115.0 65920

75. Mathiesen L, Mørck TA, Poulsen MS, Nielsen JKS, Mose T, Long M, et al. Placental transfer of pesticides studied in human placental perfusion. Basic Clin Pharmacol Toxicol. (2020) 127:505-15. doi: 10.1111/bcpt.13456

76. Lin Z, Fisher JW, Wang R, Ross MK, Filipov NM. Estimation of placental and lactational transfer and tissue distribution of atrazine and its main metabolites in rodent dams, fetuses, and neonates with physiologically based pharmacokinetic modeling. Toxicol Appl Pharmacol. (2013) 273:140-58. doi: 10.1016/j.taap.2013.08.010 
77. Pitzer EM, Williams MT, Vorhees CV. Effects of pyrethroids on brain development and behavior: deltamethrin. Neurotoxicol Teratol. (2021) 87:106983. doi: 10.1016/j.ntt.2021.1 06983

78. Dallmann A, Solodenko J, Ince I, Eissing T. Applied concepts in PBPK modeling: how to extend an open systems pharmacology model to the special population of pregnant women: pregnancy PBPK models in open systems pharmacology. CPT Pharmacomet Syst Pharmacol. (2018) 7:419-31. doi: $10.1002 /$ psp 4.12300

Conflict of Interest: The authors declare that the research was conducted in the absence of any commercial or financial relationships that could be construed as a potential conflict of interest.
Publisher's Note: All claims expressed in this article are solely those of the authors and do not necessarily represent those of their affiliated organizations, or those of the publisher, the editors and the reviewers. Any product that may be evaluated in this article, or claim that may be made by its manufacturer, is not guaranteed or endorsed by the publisher.

Copyright (๑) 2021 Personne, Brochot, Marcelo, Corona, Desmots, Robidel, Lecomte, Bach and Zeman. This is an open-access article distributed under the terms of the Creative Commons Attribution License (CC BY). The use, distribution or reproduction in other forums is permitted, provided the original author(s) and the copyright owner(s) are credited and that the original publication in this journal is cited, in accordance with accepted academic practice. No use, distribution or reproduction is permitted which does not comply with these terms. 